\title{
Risk factors for mortality in patients undergoing continuous renal replacement therapy after cardiac surgery
}

\author{
Chang Liu ${ }^{1,6 \dagger}$, Hai-Tao Zhang ${ }^{2 \dagger}$, Li-Jun Yue ${ }^{3}$, Ze-Shi Li ${ }^{2}$, Ke Pan ${ }^{4}$,Zhong Chen ${ }^{5}$, Su-Ping Gu ${ }^{6}$, Tuo Pann ${ }^{2,6}$, \\ Jun Pan ${ }^{1,6^{*}}$ and Dong-Jin Wang $1,2,4,5,6^{*}$
}

\begin{abstract}
Background: To investigate the risk factors for mortality in patients with acute kidney injury requiring continuous renal replacement therapy (AKI-CRRT) after cardiac surgery.

Methods: In this retrospective study, patients who underwent AKI-CRRT after cardiac surgery in our centre from January 2015 to January 2020 were included. Univariable and multivariable analyses were performed to identify the risk factors for in-hospital mortality.

Results: A total of 412 patients were included in our study. Of these, 174 died after AKI-CRRT, and the remaining 238 were included in the survival control group. Multivariable logistic regression analysis revealed that EuroSCORE $>7$ (odds ratio $[\mathrm{OR}], 3.72 ; 95 \%$ confidence interval $[\mathrm{Cl}], 1.92-7.24 ; \mathrm{p}<0.01)$, intraoperative bleeding $>1 \mathrm{~L}(\mathrm{OR}, 2.14 ; 95 \% \mathrm{Cl}$, $1.19-3.86 ; \mathrm{p}=0.01)$ and mechanical ventilation time $>70 \mathrm{~h}(\mathrm{OR}, 5.03 ; 95 \% \mathrm{Cl}, 2.40-10.54 ; \mathrm{p}<0.01)$ were independent risk factors for in-hospital mortality in patients who had undergone AKI-CRRT. Our study also found that the use of furosemide after surgery was a protective factor for such patients (odds ratio, 0.48 ; 95\% confidence interval, $0.25-0.92$; $p=0.03$ ).

Conclusions: In summary, the mortality of patients with AKI-CRRT after cardiac surgery remains high. The EuroSCORE, intraoperative bleeding and mechanical ventilation time were independent risk factors for in-hospital mortality. Continuous application of furosemide may be associated with a better outcome.
\end{abstract}

\section{Background}

Acute kidney injury (AKI) is a common complication after cardiac surgery, with an incidence of approximately $30 \%[1,2]$. Among patients who experience AKI, $2 \%$ to $5 \%$ require continuous renal replacement therapy

*Correspondence: pj791028@163.com; dongjin_wang@126.com ${ }^{\dagger}$ Chang Liu and Hai-Tao Zhang contributed equally to this work

1 Department of Cardio-Thoracic Surgery, Nanjing Drum Tower Hospital Clinical College of Traditional Chinese and Western Medicine, Nanjing University of Chinese Medicine, Number 321 Zhongshan Road, Nanjing 210008, Jiangsu, China

Full list of author information is available at the end of the article
(CRRT) $[3,4]$, and their mortality rate ranges from 50 to $80 \%[5,6]$.

The identification of risk factors in cardiac surgery patients with AKI requiring CRRT (AKI-CRRT) may help in patient stratification, resulting in more appropriate resource utilization and improving patient prognosis $[5,7]$. However, although many studies have investigated the risk factors for AKI in patients after cardiac surgery, few studies have focused on patients with AKI-CRRT [8, 9]. In existing research on the risk factors for AKI-CRRT, the sample size of the experimental group is small $[8,9]$. Therefore, the purpose of this study was to assess the risk 
factors for mortality in patients who underwent AKICRRT after cardiac surgery.

\section{Methods}

\section{Study design and settings}

Ethical approval for this retrospective study was obtained from the Medical Ethics Committee of Affiliated Nanjing Drum Tower Hospital, Nanjing University Medical College (2020-281-01), and the study was conducted according to the principles of the Declaration of Helsinki.

We continuously included patients with AKI-CRRT in our centre from January 2015 to January 2020. A total of 412 patients met the eligibility criteria, including 174 patients who died in the hospital and 238 surviving patients included as the control group.

\section{Surgical techniques and cardiopulmonary bypass}

Median sternotomy and cardiopulmonary bypass (CPB) were used for all patients. The ascending aorta was cannulated with a patient size-appropriate cannula. Venous cannulations were performed with separate cannulas in the superior and inferior venae cavae. The initial volume of the antegrade cold blood cardioplegia solution (4:1 cardioplegia solution to blood ratio) was twice the volume needed for the cessation of all cardiac electrical activity but never less than $1,000 \mathrm{~m}$. Cardiac arrest was maintained by retrograde infusion of $300 \mathrm{~mL}$ of blood cardioplegia solution (8:1 cardioplegia solution to blood ratio) every $20 \mathrm{~min}$. Occasionally, intermittent antegrade cold blood cardioplegia was used according to the surgeon's preferences [10].

\section{Usage of CRRT and diuretics}

The CRRT mode used in our study was continuous venous-venous hemodiafiltration (CVVHDF). During CRRT, patients were typically administered oral diuretics (furosemide and torsemide). The usual initial dose of furosemide was $20 \mathrm{mg}$, administered once daily. If needed, the same dose was administered 6 to $8 \mathrm{~h}$ later. The usual initial dose of torsemide was $10 \mathrm{mg}$, also administered orally once daily. If the diuretic response was not satisfactory, the dose of torsemide could be increased to $20 \mathrm{mg}$ once daily.

\section{Diagnostic criteria of AKI-CRRT}

1. Anuria (negligible urine output for $6 \mathrm{~h}$ ); 2 . Severe oliguria (urine output $<200 \mathrm{~mL}$ over $12 \mathrm{~h}$ ); 3 . Hyperkalaemia (serum potassium concentration $>6.5 \mathrm{mmol} / \mathrm{L}$ ); 4. Severe metabolic acidosis $(\mathrm{pH}<7.2$ despite normal or low partial pressure of carbon dioxide in arterial blood); 5. Volume overload (especially pulmonary oedema unresponsive to diuretics); 6 . Pronounced azotaemia (urea concentrations $>30 \mathrm{mmol} / \mathrm{L}$ or creatinine concentrations $>300 \mu \mathrm{mol} / \mathrm{L}) ; 7$. Clinical complications of uraemia (e.g., encephalopathy, pericarditis, neuropathy) [11].

\section{Statistical analyses}

IBM SPSS statistical software was used (Statistics for Windows, version 26, IBM Corporation, Armonk, NY, USA). The normality of the distribution of continuous variables was assessed by the Shapiro-Wilk test. Normally distributed variables are expressed as the mean \pm standard deviation and were compared using Student's t-test. Nonparametric continuous variables are expressed as medians (interquartile ranges (IQRs)) and were compared using the Mann-Whitney U test. Categorical data were compared using the chi-square test or Fisher's exact test.

For additional analyses, all statistically significant variables in univariable analysis $(\mathrm{P}<0.05)$ and variables considered by clinicians to be potentially significant were included in a multivariable logistic regression model to assess the independent associated postoperative mortality in patients with AKI-CRRT. Collinearity diagnostics were performed using tolerance estimates for individual variables in a logistic regression model.

\section{Results}

\section{Patient characteristics}

During the study period, 8477 patients were admitted to our centre, and the incidence of AKI-CRRT after cardiac surgery in our centre was approximately $4.9 \%$, which is consistent with previous reports [12,13]. Finally, 412 patients were included in our study. A total of 174 patients died after AKI-CRRT (mortality group), and the remaining 238 patients were included in the survival control group. No significant differences were found regarding sex, weight, New York Heart Association (NYHA) class, preoperative left ventricular ejection fraction, preoperative left ventricular end-diastolic diameter, or previous medical history between the two groups $(\mathrm{P}>0.05)$. Compared with the control group, patients in the mortality group were older $(61.59 \pm 11.77$ vs. $57.99 \pm 12.34$, $\mathrm{P}=0.003)$. A higher EuroSCORE $(7.11 \pm 2.18$ vs. $4.85 \pm 2.37, \mathrm{P}<0.001)$ and evaluated pulmonary artery pressure (PAP; $49.78 \pm 15.52$ vs. $46.64 \pm 13.49, \mathrm{P}=0.048$ ) increased the mortality of patients with AKI-CRRT (Table 1).

\section{Intraoperative and postoperative variables} between the mortality and survival control group

There were no significant differences in the type of cardiac surgery or the proportion of atrial fibrillation ablation and deep hypothermic circulatory arrest (DHCA) between patients. However, patients who 
Table 1 Preoperative baseline and characteristics among the mortality and control groups

\begin{tabular}{|c|c|c|c|}
\hline Variable & Control $(n=238)$ & Mortality $(n=174)$ & $p$ value \\
\hline Age (year) & $57.99 \pm 12.34$ & $61.59 \pm 11.77$ & 0.003 \\
\hline Gender (male, \%) & 160,67 & 110,63 & 0.398 \\
\hline Weight (kg) & $64.26 \pm 12.36$ & $63.16 \pm 10.52$ & 0.343 \\
\hline NYHA class (n, \%) & & & 0.238 \\
\hline 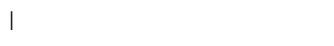 & 8,3 & 6,3 & \\
\hline$\|$ & 66,28 & 60,34 & \\
\hline III & 142,60 & 92,53 & \\
\hline IV & 22,9 & 16,9 & \\
\hline EuroSCORE & $4.85 \pm 2.37$ & $7.11 \pm 2.18$ & $<0.001$ \\
\hline \multicolumn{4}{|l|}{ Echocardiogram variables } \\
\hline Preoperative LVEF (\%) & $30.84 \pm 3.97$ & $31.02 \pm 4.03$ & 0.640 \\
\hline Preoperative LVDd (cm) & $7.04 \pm 1.10$ & $6.95 \pm 1.03$ & 0.374 \\
\hline Evaluated PAP (mmHg) & $46.64 \pm 13.49$ & $49.78 \pm 15.52$ & 0.048 \\
\hline \multicolumn{4}{|l|}{ Previous medical History ( $n, \%)$} \\
\hline Acute myocardial infarction & 61,26 & 39,22 & 0.452 \\
\hline Atrial fibrillation & 56,24 & 39,22 & 0.791 \\
\hline Diabetes mellitus & 26,11 & 20,11 & 0.856 \\
\hline Chronic renal disease & 4,2 & 3,2 & 0.937 \\
\hline Hypertension & 65,27 & 41,24 & 0.390 \\
\hline Liver diseases & 8,3 & 6,3 & 0.962 \\
\hline COPD & 15,6 & 4,2 & 0.056 \\
\hline Cancer & 3,1 & 3,2 & 0.698 \\
\hline Smoking & 46,19 & 35,20 & 0.843 \\
\hline Excessive alcohol & 20,8 & 15,9 & 0.938 \\
\hline lodine contrast medium use & 228,96 & 169,97 & 0.768 \\
\hline Vancomycin use & 4,2 & 2,1 & 0.658 \\
\hline Gentamicin use & 0 & 0 & - \\
\hline Others renal-injury drug & 2,1 & 5,3 & 0.115 \\
\hline
\end{tabular}

NYHA: New York Heart Association, COPD: Chronic obstructive pulmonary disease, LVDd: Left ventricular end-diastolic diameter, LVEF: Left ventricular ejection fraction, PAP: Pulmonary artery pressure, Means \pm SD

died in the hospital had longer CPB $(200.12 \pm 61.70$ vs. $180.93 \pm 66.68, \mathrm{P}=0.003)$ and aortic cross clamp (ACC) durations $(149.41 \pm 50.15$ vs. $130.74 \pm 54.05, \mathrm{P}<0.001)$ (Table 2).

Although patients in the mortality group had more bleeding during the operation (median: $900 \mathrm{~mL}$, IQR: 600-1200 mL vs. median: $700 \mathrm{~mL}$, IQR: $400-1000 \mathrm{~mL}$, $\mathrm{P}=0.001$ ) and received more fresh frozen plasma (FFP; 60 vs. $47 \mathrm{P}=0.002$ ), there were no significant differences in the amount of red blood cells $(\mathrm{RBCs} ; \mathrm{P}=0.089)$ or other colloid products $(\mathrm{P}=0.857)$ transfused between the two groups (Table 2).

Patients in the mortality group had a greater drainage volume in the first $24 \mathrm{~h}$ after surgery (median: $205 \mathrm{~mL}$, IQR: $100-600 \mathrm{~mL}$ vs. median: $40 \mathrm{~mL}$, IQR: $0-475 \mathrm{~mL}$, $\mathrm{P}<0.001)$. Patients in the mortality group who underwent reoperation (17 vs. $8, \mathrm{P}=0.009$ ), experienced septic shock ( 8 vs. $0, \mathrm{P}<0.001$ ), and required extracorporeal membrane oxygenation (ECMO; 10 vs. $1, \mathrm{P}=0.001$ ) and used of an intra-aortic balloon pump (IABP; 18 vs. 5, $\mathrm{P}<0.001)$ were higher. Moreover, patients in the mortality group required use of mechanical ventilation for a longer time (median: $68 \mathrm{~h}, \mathrm{IQR}: 63-74 \mathrm{~h}$ vs. median: 28 h, IQR: $23-34 \mathrm{~h}, \mathrm{P}<0.001$ ) and required longer stays in the intensive care unit $(20.55 \pm 7.20 \mathrm{~h}$ vs. $9.32 \pm 2.50 \mathrm{~h}$, $\mathrm{P}<0.001$ ) (Table 2).

The proportion of patients in the survival group who used torsemide was higher ( 90 vs. $49, \mathrm{P}=0.038$ ). However, the use of furosemide, tolvaptan or Jin-Shui Bao capsules was not different between the two groups (Table 2).

\section{Multivariable analysis between the mortality and survival control groups}

The variables that were finally entered into the multivariable logistic regression included age $>70$ years, Euro$\mathrm{SCORE}>7$, evaluated $\mathrm{PAP}>55 \mathrm{mmHg}, \mathrm{CPB}>240 \mathrm{~min}$, DHCA, intraoperative bleeding $>1 \mathrm{~L}$, intraoperative 
Table 2 Intraoperative and postoperative variables among the Mortality and Control groups

\begin{tabular}{|c|c|c|c|}
\hline Variable & Control $(n=238)$ & Mortality $(n=174)$ & $\mathrm{p}$ value \\
\hline \multicolumn{4}{|l|}{ Intraoperative variables } \\
\hline Type of cardiac surgery (n, \%) & & & 0.657 \\
\hline CABG & 43,18 & 32,18 & \\
\hline AVR & 10,4 & 7,4 & \\
\hline MVR & 86,36 & 66,38 & \\
\hline$A V R+M V R$ & 50,21 & 40,23 & \\
\hline CABG + valvular surgery & 8,3 & 3,2 & \\
\hline David/Wheats/Bentall procedure & 26,11 & 21,12 & \\
\hline Other aortic surgery & 10,4 & 5,3 & \\
\hline Atrial fibrillation ablation (n, \%) & 40,17 & 23,13 & 0.318 \\
\hline CPB (minutes) & $180.93 \pm 66.68$ & $200.12 \pm 61.70$ & 0.003 \\
\hline ACC (minutes) & $130.74 \pm 54.05$ & $149.41 \pm 50.15$ & $<0.001$ \\
\hline $\mathrm{DHCA}(\mathrm{n}, \%)$ & 10,4 & 15,9 & 0.063 \\
\hline Intraoperative bleeding (ml) & $700(400-1000)$ & $900(600-1200)$ & 0.001 \\
\hline RBC transfusion $(n, \%)$ & & & 0.089 \\
\hline$<500 \mathrm{ml}$ & 53,22 & 39,22 & \\
\hline 500-1000 ml & 141,59 & 79,45 & \\
\hline $\mathrm{ml}$ & 26,11 & 48,28 & \\
\hline$>1500 \mathrm{ml}$ & 18,8 & 8,5 & \\
\hline FFP transfusion $(n, \%)$ & 47,20 & 60,34 & 0.002 \\
\hline Other colloid products (n, \%) & 22,9 & 17,10 & 0.857 \\
\hline \multicolumn{4}{|l|}{ Postoperative outcomes } \\
\hline Drainage on the POD1 (ml) & $40(0-475)$ & $205(100-600)$ & $<0.001$ \\
\hline Re-operation $(n, \%)$ & 8,3 & 17,10 & 0.009 \\
\hline Septic shock (n, \%) & 0 & 8,5 & $<0.001$ \\
\hline ECMO use $(n, \%)$ & $1,0.4$ & 10,6 & 0.001 \\
\hline IABP use $(n, \%)$ & 5,2 & 18,10 & $<0.001$ \\
\hline Mechanical ventilation time (hours) & $28(23-34)$ & $68(63-74)$ & $<0.001$ \\
\hline ICU stay time (days) & $9.32 \pm 2.50$ & $20.55 \pm 7.20$ & $<0.001$ \\
\hline \multicolumn{4}{|l|}{ Renal protection drugs } \\
\hline Furosemide $(n, \%)$ & 196,82 & 127,73 & 0.061 \\
\hline Torasemide (n, \%) & 90,38 & 49,28 & 0.038 \\
\hline Tolvaptan (n, \%) & 63,26 & 36,21 & 0.175 \\
\hline Jin-Shui Bao capsule (n, \%) & 214,90 & 146,84 & 0.070 \\
\hline
\end{tabular}

CABG: Coronary artery bypass grafting, AVR: Aortic valve replacement/repair, MVR: Mitral valve replacement/repair, CPB: Cardiopulmonary bypass, ACC: Aortic Cross Clamp, Mean \pm SD / Median (interquartile range), DHCA: Deep hypothermic circulatory arrest, POD1: The first postoperative day, ARDS: Acute Respiratory Distress Syndrome, IABP: Intra-aortic balloon pump, RBC: Red blood cell, ECMO: Extracorporeal membrane oxygenation, ICU: Intensive care unit, FFP: Fresh frozen plasma

RBC transfusion, intraoperative FFP transfusion, drainage on POD1 $>500 \mathrm{~mL}$, reoperation, ECMO use, IABP use, mechanical ventilation time $>70 \mathrm{~h}$, postoperative furosemide, postoperative torasemide, and postoperative Jin-Shui Bao capsules. We found that EuroSCORE $>7$, intraoperative bleeding $>1 \mathrm{~L}$ and mechanical ventilation time $>70 \mathrm{~h}$ were independent risk factors for in-hospital mortality in patients who underwent AKI-CRRT. The use of furosemide after surgery was a protective factor for these patients (odds ratio, 0.48; 95\% confidence interval, $0.25-0.92 ; \mathrm{p}=0.03)($ Table 3$)$.

\section{Discussion}

This retrospective study included more than 400 patients who required AKI-CRRT after undergoing cardiac surgery, representing approximately $4.9 \%$. We found that a EuroSCORE $>7$, massive intraoperative bleeding and prolonged mechanical ventilation time were independent risk factors for mortality in patients with AKI-CRRT, while continuous use of furosemide may be associated with a better outcome.

The EuroSCORE II is widely used to predict mortality after cardiac surgery [14]. Halpin and colleagues reported 
Table 3 Multivariable analysis of factors that may be associated with mortality

\begin{tabular}{lllr}
\hline Variable & Odds ratio & $\begin{array}{l}\text { 95\% } \\
\text { Confidence } \\
\text { Interval }\end{array}$ & p value \\
\hline Age $>$ 70 years & 1.50 & $0.73-3.11$ & 0.27 \\
EuroSCORE $>7$ & 3.72 & $1.92-7.24$ & $<0.01$ \\
Evaluated PAP $>55 \mathrm{mmHg}$ & 0.64 & $0.343-1.21$ & 0.17 \\
CPB $>240$ min & 0.83 & $0.41-1.67$ & 0.60 \\
DHCA & 2.12 & $0.81-5.54$ & 0.13 \\
Intraoperative bleeding $>1 \mathrm{~L}$ & 2.14 & $1.19-3.86$ & 0.01 \\
Intraoperative RBC transfusion & 0.96 & $0.64-1.44$ & 0.85 \\
Intraoperative FFP transfusion & 1.81 & $0.89-3.66$ & 0.10 \\
Drainage on the POD1 $>500 \mathrm{ml}$ & 0.85 & $0.46-1.58$ & 0.61 \\
Re-operation & 1.11 & $0.27-4.54$ & 0.88 \\
ECMO use & 2.12 & $0.14-31.35$ & 0.58 \\
IABP use & 3.33 & $0.84-13.24$ & 0.88 \\
Mechanical ventilation & 5.03 & $2.40-10.54$ & $<0.01$ \\
time $>$ 70 $\mathrm{h}$ & & & \\
Postoperative furosemide & 0.48 & $0.25-0.92$ & 0.03 \\
Postoperative torasemide & 0.80 & $0.46-1.39$ & 0.43 \\
Postoperative jin-shui bao capsule & 0.92 & $0.38-2.25$ & 0.86 \\
\hline
\end{tabular}

The continuous variables were converted to binary variables by upper quartile ( $\geq 75$ th percentile)

PAP: Pulmonary artery pressure, CPB: Cardiopulmonary bypass, ACC: Aortic Cross Clamp, DHCA: Deep hypothermic circulatory arrest, POD1: The first postoperative day, ECMO: Extracorporeal membrane oxygenation, IABP: Intraaortic balloon pump; ICU: Intensive care unit

that the EuroSCORE II had better predictive discrimination for operative mortality than the EuroSCORE I and the Society of Thoracic Surgeons (STS) risk score [15]. Interestingly, David and colleagues also reported that the EuroSCORE could be used to predict postoperative AKI [16]. Moreover, Drosos and colleagues suggested that patients with a higher EuroSCORE II were more likely to require renal replacement therapy after cardiac surgery (7.8 \pm 14.4 vs. $1.9 \pm 2.1, \mathrm{P}=0.014)$ [17]. In our study, the EuroSCORE II values of deceased patients were higher, which is in line with previous experiences.

Intraoperative bleeding may be affected by patient- and surgery-related factors, such as the use of anticoagulants, systemic inflammatory responses, the consumption and dilution of clotting factors, and fibrinolysis associated with the use of CPB [18]. Among them, approximately $15 \%-20 \%$ of patients have excessive bleeding during cardiac surgery and consume approximately $80 \%$ of blood products used in cardiac surgery procedures [19]. Haemodynamic instability caused by excessive blood loss is an important cause of AKI [20], and the mortality of patients after surgery is also significantly increased [21]. In our centre, Stanford type A aortic dissection patients undergoing emergency surgery account for $15 \%$ of all cardiac surgery patients. Therefore, the amount of surgical blood loss and the use of AKI-CRRT in our centre are relatively high.

In addition to the EuroSCORE II, massive intraoperative bleeding was another risk factor for mortality in patients with AKI-CRRT. Bleeding is a determinant of excessive haemodilution during cardiac surgery, and the lowest haematocrit is widely recognized as related to AKI [22-25]. The main explanation for this association is that first, the increase in renal tubular transport leads to an increase in kidney energy requirements. Second, the reduced oxygen delivery caused by haemodilution can exacerbate renal ischaemic dysfunction, especially in the renal medulla, which is sensitive to oxygen [20, 21, 24]. Unlike intraoperative bleeding, the impact of blood transfusion on AKI after cardiac surgery remains controversial. Some studies contend that blood transfusion worsens CPB-initiated systemic inflammatory response syndrome with a second inflammatory response, thereby increasing the incidence of AKI [26]; in contrast, $\mathrm{Ng}$ et al. reported that blood transfusion did not play a role in influencing AKI outcomes [25]. In our study, multivariable regression analysis showed that blood transfusion was not related to the mortality of patients with AKI-CRRT after cardiac surgery. Considering that low haematocrit increases the incidence of AKI and patient mortality, we recommend that blood transfusions be properly used to avoid excessive haemodilution.

Systemic inflammatory response syndrome caused by $\mathrm{CPB}$ often leads to AKI and acute lung injury that requires positive-pressure mechanical ventilation (MV) $[27,28]$. There is a complicated internal connection between kidney and lung organ dysfunction, broadly categorized as haemodynamic and neurohormonal [27]. Multiple systematic reviews have shown that MV can greatly increase the incidence of AKI in critically ill patients [28, 29]. In addition, Fuhrman et al. reported that AKI was associated with a longer duration of MV after cardiac procedures (OR, 1.47; 95\% CI: 1.15-1.89) [30]. Therefore, we suggest that it may be beneficial to withdraw MV as soon as possible for patients undergoing AKI-CRRT, but further research and verification are needed to support this claim.

Multivariable regression analysis showed that continuous use of furosemide after surgery was a protective factor that may reduce the mortality of patients with AKI-CRRT. For AKI-CRRT patients, the value of diuretics remains controversial. A recent large-scale cohort study supports our conclusion, however, suggesting that the difference in evaluation criteria was the cause of the controversy over the value of diuretics. The study authors reported that continuous infusion of furosemide increased urine output and helped with successful CRRT 
discontinuation [31]. However, a previous systematic review reported that furosemide is not associated with significant clinical benefits on renal outcome, including in-hospital mortality and renal replacement therapy or dialysis [32]. In addition, Vargas et al. suggested that torsemide might show a better dose-dependent diuretic effect in patients after CRRT treatment [33]. In our research, both torsemide $(\mathrm{P}=0.038)$ and the traditional Chinese medicine Jin-Shui Bao capsule $(\mathrm{P}=0.070)$ showed potential value in protecting kidney function, but both need to be verified by specially designed clinical trials.

\section{Limitation}

Some limitations should be considered in this study. First, because of the retrospective study design, some predictors of AKI prognosis, such as fractional excretion of urea, the furosemide stress test and creatinine clearance assessed by $6-\mathrm{h}$ urine, were not included. Second, also related to the retrospective nature of the study, many confounding factors may have affected the reliability of our conclusions, and our research suggests that oral furosemide during AKI-CRRT after cardiac surgery may be beneficial, but further research is necessary. Third, in the multivariable regression analysis, continuous variables were converted to binary variables by upper quartile ( $>75$ th percentile), which may lead to partial loss of information. Finally, the data come from a single centre, and agency-specific variables may have influenced the current results. Future studies will focus on improving the generalization and practicability of the research results.

\section{Conclusion}

In summary, the mortality of patients with AKI-CRRT after cardiac surgery remains high. The EuroSCORE, intraoperative bleeding and mechanical ventilation time were independent risk factors for in-hospital mortality. Continuous use of furosemide may be associated with a better outcome.

\section{Acknowledgements}

Not applicable.

\section{Authors' contributions}

(I) Conception and design: Dong-Jin Wang, Jun Pan; (II) Administrative support: Dong-Jin Wang, Jun Pan; (III) Provision of study materials or patients: Dong-Jin Wang, Jun Pan; (IV) Collection and assembly of data: Chang Liu, Hai-Tao Zhang, Li-Jun Yue, Ze-Shi Li, Ke Pan, Zhong Chen, Su-Ping Gu, Tuo Pan; (V) Data analysis and interpretation: Chang Liu, Hai-Tao Zhang, Li-Jun Yue; (VI) Manuscript writing. All authors read and approved the final manuscript.

\section{Funding}

This work was supported by Jiangsu Provincial Key Medical Discipline of The Project of Invigorating Health Care through Science, Technology and Education. Grant number ZDXKA2016019.

\section{Availability of data and materials}

The datasets used and/or analysed during the current study are available from the corresponding author on reasonable request.

\section{Declarations}

Ethics approval and consent to participate

Patients, or their relatives when the patients could not consent, provided written informed consent for participation in the study. Ethical approval was obtained from the Medical Ethics Committee of Affiliated Nanjing Drum Tower Hospital, Nanjing University Medical College (2020-249-01), and the study was conducted according to the principles of the Declaration of Helsinki.

\section{Consent for publication}

Not applicable.

\section{Competing interests}

The authors declare that they have no known competing financial interests or personal relationships that could have appeared to influence the work reported in this paper.

\section{Author details}

${ }^{1}$ Department of Cardio-Thoracic Surgery, Nanjing Drum Tower Hospital Clinical College of Traditional Chinese and Western Medicine, Nanjing University of Chinese Medicine, Number 321 Zhongshan Road, Nanjing 210008, Jiangsu, China. ${ }^{2}$ Department of Cardio-Thoracic Surgery, Nanjing Drum Tower Hospital, Peking Union Medical College, Chinese Academy of Medical Sciences, Graduate School of Peking Union Medical College, Beijing 100010, China. ${ }^{3}$ Department of Traditional Chinese Medicine, Nanjing Drum Tower Hospital, The Affiliated Hospital of Nanjing University Medical School, Nanjing 210008, Jiangsu, China. ${ }^{4}$ Nanjing Drum Tower Hospital, The Affiliated Clinical College of Xuzhou Medical University, Nanjing 210008, Jiangsu, China. ${ }^{5}$ Department of Cardio-Thoracic Surgery, Nanjing Drum Tower Hospital, Nanjing Medical University, Nanjing 210008, Jiangsu, China. ${ }^{6}$ Department of Cardio-Thoracic Surgery, Nanjing Drum Tower Hospital, The Affiliated Hospital of Nanjing University Medical School, Nanjing 210008, Jiangsu, China.

Received: 1 May 2021 Accepted: 14 October 2021

Published online: 21 October 2021

\section{References}

1. Lagny MG, Jouret F, Koch JN, et al. Incidence and outcomes of acute kidney injury after cardiac surgery using either criteria of the RIFLE classification. BMC Nephrol. 2015;16:76. https://doi.org/10.1186/ s12882-015-0066-9.

2. Hoste EA, Cruz DN, Davenport A, et al. The epidemiology of cardiac surgery-associated acute kidney injury. Int J Artif Organs. 2008;31(2):15865. https://doi.org/10.1177/039139880803100209.

3. Mehta RH, Grab JD, O'Brien SM, et al. Bedside tool for predicting the risk of postoperative dialysis in patients undergoing cardiac surgery. Circulation. 2006;114(21):2208-16; (quiz 08). https://doi.org/10.1161/CIRCU LATIONAHA.106.635573.

4. Wijeysundera DN, Karkouti K, Dupuis JY, et al. Derivation and validation of a simplified predictive index for renal replacement therapy after cardiac surgery. JAMA. 2007;297(16):1801-9. https://doi.org/10.1001/jama.297.16. 1801.

5. Kowalik MM, Lango R, Klajbor K, et al. Incidence- and mortality-related risk factors of acute kidney injury requiring hemofiltration treatment in patients undergoing cardiac surgery: a single-center 6-year experience. J Cardiothorac Vasc Anesth. 2011;25(4):619-24. https://doi.org/10.1053/j. jvca.2010.12.011.

6. Thakar CV, Worley S, Arrigain S, et al. Influence of renal dysfunction on mortality after cardiac surgery: modifying effect of preoperative renal function. Kidney Int. 2005;67(3):1112-9. https://doi.org/10.1111/j.15231755.2005.00177.x.

7. Hein OV, Birnbaum J, Wernecke KD, et al. Three-year survival after four major post-cardiac operative complications. Crit Care Med. 
2006;34(11):2729-37. https://doi.org/10.1097/01.CCM.0000242519.71319. $A D$.

8. Wu HB, Ma WG, Zhao HL, et al. Risk factors for continuous renal replacement therapy after surgical repair of type A aortic dissection. J Thorac Dis. 2017;9(4):1126-32. https://doi.org/10.21037/jtd.2017.03.128.

9. Lin JJ. Renal support for pediatric patients with acute kidney injury after cardiac surgery. What do we know now? Rev Esp Cardiol (Engl Ed). 2012;65(9):785-7. https://doi.org/10.1016/j.recesp.2012.04.015.

10. Fan FD, Zhang HT, Pan T, et al. Evaluation of beta-blocker therapy for long-term outcomes in patients with low ejection fraction after cardiac surgery. BMC Cardiovasc Disord. 2020;20(1):379. https://doi.org/10.1186/ s12872-020-01651-6.

11. Bellomo R, Kellum JA, Ronco C. Acute kidney injury. The Lancet. 2012;380(9843):756-66. https://doi.org/10.1016/s0140-6736(11)61454-2.

12. Santiago MJ, Lopez-Herce J, Urbano J, et al. Continuous renal replacement therapy in children after cardiac surgery. J Thorac Cardiovasc Surg. 2013;146(2):448-54. https://doi.org/10.1016/j.jtcvs.2013.02.042.

13. Aittokallio J, Uusalo $P$, Kallioinen $M$, et al. Markers of poor prognosis in patients requiring continuous renal replacement therapy after cardiac surgery. J Cardiothorac Vasc Anesth. 2020;34(12):3329-35. https://doi.org/ 10.1053/j.jvca.2020.04.055

14. Nashef SA, Roques F, Sharples LD, et al. EuroSCORE II. Eur J Cardiothorac Surg. 2012;41 (4):734-44; (discussion 44-5). https://doi.org/10.1093/ ejcts/ezs043.

15. Ad N, Holmes SD, Patel J, et al. Comparison of EuroSCORE II, original EuroSCORE, and the society of thoracic surgeons risk score in cardiac surgery patients. Ann Thorac Surg. 2016;102(2):573-9. https://doi.org/10.1016/j. athoracsur.2016.01.105.

16. Duthie FA, McGeehan P, Hill S, et al. The utility of the additive EuroSCORE, RIFLE and AKIN staging scores in the prediction and diagnosis of acute kidney injury after cardiac surgery. Nephron Clin Pract. 2014;128(1-2):2938. https://doi.org/10.1159/000357675.

17. Drosos G, Ampatzidou F, Sarafidis P, et al. Serum creatinine and chronic kidney disease-epidemiology estimated glomerular filtration rate: independent predictors of renal replacement therapy following cardiac surgery. Am J Nephrol. 2018;48(2):108-17. https://doi.org/10.1159/00049 2182.

18. Karkouti K, McCluskey SA, Syed S, et al. The influence of perioperative coagulation status on postoperative blood loss in complex cardiac surgery: a prospective observational study. Anesth Analg. 2010;110(6):153340. https://doi.org/10.1213/ANE.0b013e3181db7991.

19. Society of Thoracic Surgeons Blood Conservation Guideline Task F, Ferraris VA, Brown JR, et al. 2011 update to the Society of Thoracic Surgeons and the Society of Cardiovascular Anesthesiologists blood conservation clinical practice guidelines. Ann Thorac Surg. 2011;91(3):944-82. https:// doi.org/10.1016/j.athoracsur.2010.11.078.

20. Rosner MH, Okusa MD. Acute kidney injury associated with cardiac surgery. Clin J Am Soc Nephrol. 2006;1 (1):19-32. https://doi.org/10.2215/ CJN.00240605.

21. Ranucci M, Baryshnikova E, Castelvecchio S, et al. Major bleeding, transfusions, and anemia: the deadly triad of cardiac surgery. Ann Thorac Surg. 2013;96(2):478-85. https://doi.org/10.1016/j.athoracsur.2013.03.015.
22. Tadphale SD, Ramakrishnan K, Spentzas T, et al. Impact of different cardiopulmonary bypass strategies on renal injury after pediatric heart surgery. Ann Thorac Surg. 2021;111(4):1374-9. https://doi.org/10.1016/j. athoracsur.2020.05.056.

23. Mehta RH, Castelvecchio S, Ballotta A, et al. Association of gender and lowest hematocrit on cardiopulmonary bypass with acute kidney injury and operative mortality in patients undergoing cardiac surgery. Ann Thorac Surg. 2013;96(1):133-40. https://doi.org/10.1016/j.athoracsur. 2013.03.033.

24. Swaminathan M, Phillips-Bute BG, Conlon PJ, et al. The association of lowest hematocrit during cardiopulmonary bypass with acute renal injury after coronary artery bypass surgery. Ann Thorac Surg. 2003;76(3):784-91. https://doi.org/10.1016/s0003-4975(03)00558-7.

25. Ng RR, Chew ST, Liu W, et al. Identification of modifiable risk factors for acute kidney injury after coronary artery bypass graft surgery in an Asian population. J Thorac Cardiovasc Surg. 2014;147(4):1356-61. https://doi. org/10.1016/j.jtcvs.2013.09.040.

26. Fransen $\mathrm{E}$, Maessen J, Dentener $\mathrm{M}$, et al. Impact of blood transfusions on inflammatory mediator release in patients undergoing cardiac surgery. Chest. 1999;116(5):1233-9. https://doi.org/10.1378/chest.116.5.1233.

27. Koyner JL, Murray PT. Mechanical ventilation and the kidney. Blood Purif. 2010;29(1):52-68. https://doi.org/10.1159/000259585.

28. van den Akker JP, Egal M, Groeneveld AB. Invasive mechanical ventilation as a risk factor for acute kidney injury in the critically ill: a systematic review and meta-analysis. Crit Care. 2013;17(3):R98. https://doi.org/10. 1186/cc12743.

29. Folkestad T, Brurberg KG, Nordhuus KM, et al. Acute kidney injury in burn patients admitted to the intensive care unit: a systematic review and meta-analysis. Crit Care. 2020;24(1):2. https://doi.org/10.1186/ s13054-019-2710-4.

30. Fuhrman DY, Nguyen LG, Sanchez-de-Toledo J, et al. Postoperative acute kidney injury in young adults with congenital heart disease. Ann Thorac Surg. 2019;107(5):1416-20. https://doi.org/10.1016/j.athoracsur.2019.01. 017.

31. Jeon J, Kim DH, Baeg SI, et al. Association between diuretics and successful discontinuation of continuous renal replacement therapy in critically ill patients with acute kidney injury. Crit Care. 2018;22(1):255. https://doi. org/10.1186/s13054-018-2192-9.

32. Ho KM, Sheridan DJ. Meta-analysis of frusemide to prevent or treat acute renal failure. BMJ. 2006;333(7565):420. https://doi.org/10.1136/bmj.38902. $605347.7 \mathrm{C}$

33. Vargas Hein O, Staegemann M, Wagner D, et al. Torsemide versus furosemide after continuous renal replacement therapy due to acute renal failure in cardiac surgery patients. Ren Fail. 2005;27(4):385-92. https://doi. org/10.1081/jdi-65298.

\section{Publisher's Note}

Springer Nature remains neutral with regard to jurisdictional claims in published maps and institutional affiliations.

Ready to submit your research? Choose BMC and benefit from

- fast, convenient online submission

- thorough peer review by experienced researchers in your field

- rapid publication on acceptance

- support for research data, including large and complex data types

- gold Open Access which fosters wider collaboration and increased citations

- maximum visibility for your research: over $100 \mathrm{M}$ website views per year

At $\mathrm{BMC}$, research is always in progress.

Learn more biomedcentral.com/submissions 